\title{
A Health Assessment Tool for Multiple Risk Factors for Obesity: Psychometric Testing and Age Differences in UK Adults
}

\author{
Julie A. Chambers Vivien Swanson \\ University of Stirling, Stirling, Scotland, UK
}

\section{Key Words}

Obesity - Eating patterns · Physical activity - Multiple risk behaviours - Health assessment

\section{Summary}

Background: Although many individual health behaviours (e.g. diet/activity) have been implicated in the current rise in obesity levels, their confounding or cumulative effects have yet to be established. This study psychometrically tested a previously piloted comprehensive measure of obesity risk factors, designed to assess their relative importance at individual and population levels. Material and Methods: A user-friendly, self-report questionnaire, completed by 359 adult volunteers $(71 \%$ female, age range 18-81 years), was subjected to exploratory factor analysis and related to body mass index (BMI) and age. Results: The final solution had 74 items and showed a clear factor structure, with 5 dietary and 5 activity factors, plus 8 unrelated factors covering dieting behaviour, alcohol consumption, sleep, and varied developmental influences. Younger respondents generally reported unhealthier behaviours. Once age was controlled for, less healthy eating, more emotional eating, higher amounts eaten, less physical activity, more use of mechanised transport, and more/less successful dieting behaviour were all strongly related to higher BMI, with lesser associations for more TV watching and less parental encouragement to be active. Conclusion: This easy-touse self-report measure of multiple risk factors showed good psychometric properties and has merit in determining the contribution of varied factors in the tendency to overweight and obesity. The finding that younger adults generally reported less healthy dietary and activity behaviour indicates a pressing need for early intervention.

\section{Introduction}

Obesity is now recognised as a global epidemic [1] and has been predicted to become the largest drain on health service resources in the UK in the near future. In 2001, 59\% of all UK adults were overweight (37\%) or obese $(22 \%)$ [2], and, if left unchecked, this is estimated to reach $90 \%$ by 2050 [3]. Being overweight is associated with a wide range of health problems, including heart disease, back pain and joint problems, some cancers, higher rates of mortality, hypertension and diabetes as well as psychosocial problems $[4,5]$. The cost of these health problems, both in terms of direct costs to the National Health Service (NHS) for medical treatment, and indirect costs such as sick leave, incapacity benefit, and early mortality, are large and getting larger. Although genetic predisposition may play a part in determining which individuals are more likely to become obese, our gene pool has not changed for thousands of years, and so changes in health behaviours, including eating and activity patterns at a population level, must have been instrumental in the exponential rise in obesity rates [6]. Most current treatment programmes, and also government health initiatives, are aimed at changing one, or both, of these behaviours. However, treatment of obesity has met with limited success, particularly over the longer term. It would seem, therefore, that prevention is the best policy for reducing rates of obesity across the population [7]. Early intervention is essential and needs to be based upon a comprehensive, comparative assessment of a wide range of risk factors.

\section{Risk Factors}

Current evidence supports an association between obesity and a wide range of different risk factors including diet, eating patterns, activity levels, family background, and amount of sleep [8]. Overall food consumption has reduced as obesity levels have risen [9], suggesting that increased calorific consumption

\begin{tabular}{ll}
\hline KARGER & $\oplus$ 2008 S. Karger GmbH, Freiburg \\
Fax +497614520714 & Accessible online at: \\
$\begin{array}{l}\text { Information@Karger.de } \\
\text { www.karger.com }\end{array}$ & www.karger.com/ofa
\end{tabular}


is not related to higher levels of obesity in the population as a whole. Nonetheless, portion sizes of food have increased greatly, and eating larger portions has been linked to increased weight in individuals [10]. In addition, the type of food we eat has changed in recent years, with the resultant increased proportions of energy dense foods (i.e. fatty and sugary foods and drinks) [11, 12] and correspondingly reduced levels of complex carbohydrates [13] both being associated with obesity.

Patterns of eating have also been linked to obesity. Dieting behaviour, particularly unsuccessful repeated attempts at weight loss through calorie intake reduction (or 'yo-yo' dieting), has been associated with longer-term weight gain, especially in women [14]. Overweight adolescents are more likely to indulge in unhealthy eating behaviours such as extreme dieting or skipping breakfast than normal weight adolescents [15]. Snacking, eating out, and not eating meals as a family have all been associated with increased levels of obesity [16]. Finally, eating in response to emotional rather than hunger cues and eating when bored are both evident in overweight and obese individuals [17].

Alongside changes in eating behaviours, UK adults and children have become much less active over the last 30 years. Increasingly inactive leisure time, fewer manual jobs, the extensive use of cars even for short journeys, and labour saving devices all contribute to the population being far less active than it used to be [6]. The number of hours spent in relatively inactive pastimes such as watching TV and playing computer games have both been associated with obesity, particularly in children [18]. TV may also influence eating behaviour, either indirectly through adverts for fast and junk food, or directly by increasing snack consumption $[19,20]$. Conversely, those who take part in regular physical activity or exercise, particularly of moderate or greater intensity, are less likely to be overweight or obese [21].

Having one obese parent, particularly the mother, is a key predictor of adult obesity in offspring, irrespective of whether they were overweight as children [22,23]. Developmental factors including heavier birth weight and early maturation have also been linked to an increased risk of obesity in later life $[24,25]$, whilst being breastfed seems to serve as a protective factor [26]. Lower socio-economic status (SES) also seems to be associated with obesity in developed countries, particularly in women [27]. Finally, sleeping for fewer hours has also been associated with higher levels of obesity [28].

Many of the reported studies examining risk factors for obesity have concentrated on only 1 type of behaviour. However, where so many diverse factors have been shown to be related to increased weight, in order to gain a comprehensive picture of their relative risks and therefore to help target interventions, we will need to evaluate the effects of multiple factors concurrently. A number of studies have examined more than 1 of the key risk areas at the same time, although most of these have concentrated on aspects of diet and activity and ignored other related factors such as SES, sleep patterns, and family influ- ences (other than body mass index (BMI)). In addition, these studies have generally aimed to measure actual eating and activity behaviours and ignore psychological influences on these behaviours. In one such study of Australian children aged 5-13, Wake et al. [29] found that a model which included TV and computer usage, organised and general activity levels, food intake, and parental BMI explained around $22 \%$ of the variance in child BMI, with food intake and parental BMI explaining $11 \%$ and $5 \%$, respectively. However, many of the variables in this study were self-reported by parents, which they accepted could be biased in the case of overweight children.

Although the individual risk factors for obesity are well-documented, Müller et al. [30], in 2001, highlighted that 'their confounding or cumulative effects on the development of obesity, as well as their clustering and their effects over time ... remain unclear with respect to a given individual as well as with a greater population of subjects' (p. 20).

We have previously aimed to address this limitation by piloting a comprehensive measure of a wide range of currently identified risk factors for obesity, including psychosocial aspects of behaviour, thereby facilitating examination of their relative importance at both an individual and population level. The measure, which could be easily administered by health professionals prior to treatment, provides a comprehensive and structured framework for assessment of behaviours and as such would help identify multiple areas of high risk at an individual and population level. The pilot study [31] showed that an easy-to-complete, self-report tool can have value in assessing multiple risk factors for obesity. Here, we report on the results of exploratory factor analysis and reliability testing of this measure in a larger sample, with the aim of further establishing its usefulness as a health assessment tool for obesity. It was expected that the resulting sub-factors of risk behaviours for obesity would be associated with higher BMI.

\section{Material and Methods}

\section{Procedure}

The study consisted of a convenience sample of volunteers recruited either via response to posters displayed at a Scottish university or via personal invitation. All questionnaires were completed and returned anonymously in sealed envelopes. In addition to the risk factor questionnaire (see below), participants provided self-reported weight and height for calculation of BMI, as well as job status of self and partner for assessment of SES.

\section{Participants}

359 adults $(71 \%$ female $)$ residing in Scotland $(\mathrm{n}=268)$, England $(\mathrm{n}=79)$, and Northern Ireland $(n=4)$ completed the questionnaire between 2004 and 2007 (country of residence was undetermined for 8 respondents). The age range was 18-81 years (mean 30.8 years, standard deviation (SD) 14.0). Two-fifths of the respondents $(n=142)$ were students based at the University of Stirling; data on social class was available for 208 of the remaining 217 respondents, and there was a bias towards higher SES [32] in these adults, with $22.6 \%(\mathrm{n}=47)$ identified as SES I, 32.2\% $(\mathrm{n}=67)$ SES II, $28.8 \%(n=60)$ SES III, 10.1\% $(n=21)$ SES IV, and 6.3\% $(n=13)$ SES V. 


\section{Questionnaire}

A 100-item questionnaire was developed by generating a number of items for a wide range of reported risk factors for obesity, after extensive review of pertinent factors and measures identified from recent research [e.g. 33, 34]. The questionnaire was designed to be easy to complete. Full details of the development process are reported in the pilot study by Chambers and Swanson [31]. The adult version of the questionnaire has a Flesch [35] readability score of 69.4 , i.e. a reading age of approximately 12 years Items cover an extensive range of currently proposed risk factors for obesity, to allow comparisons between factors. Because of problems in measuring actual food consumption and activity levels, particularly in the overweight [36], we adopted a method of using items based on frequency of preferred or typical behaviour, rather than trying to assess actual be haviour. Examples of items are: 'I would rather eat out than eat at home: Almost always; Most of the time; Often; Sometimes; Rarely; Almost never', and 'On a typical day I watch TV, videos or DVDs for: At least 4 hours; 3 or 4 hours; 1 or 2 hours; Less than 1 hour; Not at all'. The questionnaire also includes items to assess psychological attitudes towards behaviour, e.g. 'Exercising makes me feel happier'; and social influences on behaviour, e.g. 'My family makes fun of me if I try and eat healthily'. Specific examples of behaviour were included where it was felt any ambiguity might occur for example: 'I take part in organised sport or other physical activities (e.g. dance class, aerobics class, athletics, football, tennis, rugby, gymnastics)'. Although items were phrased in both positive and negative directions to account for response set bias, where necessary, scores were reversed when coding, such that high scores on all items indicated behaviours acknowledged as being less healthy. After data for the pilot study was analysed, some minor modifications were made to the questionnaire. The main difference in the modified version was the addition of a question on number of weekly alcohol units consumed (rather than just frequency of drinking alcohol) plus 2 questions on success and frequency of previous (rather than only current) dietary behaviour. In this sample, 111 respondents completed the first (unmodified, 100-item) version of the questionnaire, and 248 completed the modified 103 -item version.

\section{Results}

The mean BMI of the sample (i.e. weight $(\mathrm{kg})$ divided by height $^{2}(\mathrm{~m})$ ), was 24.7 (SD 5.2), and $37.4 \%$ were considered overweight according to the recommended BMI cut-offs [37] ( $26 \%$ overweight $(\mathrm{BMI} \geq 25)$ and $11.4 \%$ obese $(\mathrm{BMI} \geq 30)$ ), $50.3 \%$ were considered of normal weight $(25>\mathrm{BMI} \geq 20)$, and $12.3 \%$ of low weight $(\mathrm{BMI}<20)$. Males $($ mean $=25.8$, SD 5.5$)$ had significantly higher BMI than females (mean $=24.3$, SD 5.0) $(\mathrm{t}(348)=2.4, \mathrm{p}=0.019,95 \%$ confidence interval $(\mathrm{CI})$ for difference $(0.2,2.6))$. The tendency of this sample to be less likely to be overweight than the national average, is almost certainly due to 2 factors: the predominance of students and the bias towards higher social class. However, although age was very strongly positively correlated with BMI ( $r=0.34$, $\mathrm{p}<0.001$ ), with younger respondents having lower BMI, the association of higher BMI with lower social class failed to reach significance in the current sample $(\mathrm{r}=0.12, \mathrm{p}=0.080)$.

\section{Factor Analysis}

Exploratory factor analysis on the questionnaire items was carried out in order to identify sub-factors of behaviours, with the additional aim of reducing the number of items in the questionnaire. This was carried out in three stages: firstly with the dietary items, secondly with the activity items, and thirdly with the remaining items relating to a range of other factors including alcohol consumption, sleep, dieting behaviour, and developmental factors (including breastfeeding, parental influence when growing up). This was because it was expected that items relating to activity and items relating to dietary or other behaviours would automatically load on separate factors. (Note: the two items relating to eating behaviour whilst watching TV were initially considered in both the dietary and activity factor analyses, and they were found only to contribute to the solution for activity behaviour.) Smoking was treated as a standalone item and not included in any factor analysis: in this sample, there was little variation in this item as the majority $(80 \%)$ of respondents were non-smokers or very occasional smokers (less than 1 a month). Also, although it is possible that higher smoking may be related to lower BMI, this is not a behaviour which could be advocated as a preventive measure for obesity. Principle components analysis (PCA) was used for these exploratory factor analyses.

\section{Dietary Items}

\section{Factor Analysis and Reliability Testing}

First, all items $(\mathrm{n}=53)$ relating to current dietary habits were entered into a PCA. There were 15 factors with eigenvalues $>1$ together explaining $64.4 \%$ of the variance. However, a scree plot showed a notable drop after the first four factors. The PCA was rerun specifying a four-factor extraction, and Direct Oblimin rotation was used in order to help clarify each solution, whilst allowing the resulting factors to be correlated. The resulting four-factor solution explained $35.8 \%$ of the total variance. Four items (relating to drinking milk, knowing when food unhealthy, preferring savoury to sweet foods, and eating out) did not load highly (i.e. loaded at $\leq 0.3$ ) on any of the resulting four factors, and these were then excluded and the PCA analysis rerun. The analysis was then repeated in an iterative process until all remaining items contributed to the solution. In total, 14 items were identified for exclusion through this process: choosing low fat foods, preferring savoury to sweet foods, frequency of eating unhealthy breakfast, eating with family, family eating same food, friends preferring fast food, rather eat out than at home, feeling hungry after snacking, snacking on the same things, frequency of eating out, drinking milk, knowing when food unhealthy, disliking eating, and wanting to try foods displayed in adverts. When these 14 items were excluded, $42.9 \%$ of the variance was explained, however, 15 of the 39 items loaded very highly on the first factor, and the scree plot suggested that a five-factor solution might be more appropriate. The result of this forced fivefactor PCA identified another item (rather eat fried foods) for exclusion, and when this was done, the solution explained $47.7 \%$ of the variance. 
Table 1. Principle components analysis with Direct Oblimin rotation for dietary items $^{\text {a }}$

\begin{tabular}{llll}
\hline & Factor & & \\
\cline { 2 - 6 } & $\begin{array}{l}\text { healthy emotional social } \begin{array}{l}\text { amount convenience } \\
\text { eating }\end{array} \\
\text { eating influences eaten }\end{array}$ \\
\hline
\end{tabular}

\section{Healthy Eating}

Frequency of eating fruit

0.708

Frequency of eating vegetables

0.549

0.532

Frequency of eating 5 servings fruit/vegetables $\quad 0.690$

Rather have healthy lunch 0.425

Frequency of eating breakfast $\quad 0.796$

Frequency of eating healthy breakfast $\quad 0.759$

Compared to others diet is less/more healthy $\quad 0.554$

Frequency of eating high-fibre foods $\quad 0.678$

Frequency of drinking fizzy drinks $\quad 0.420$

Frequency of drinking water $\quad 0.455$

Frequency of trying to eat healthily $\quad 0.612$

Frequency of eating snacks

0.536

0.502

0.768

0.748

0.672

0.506

0.458

Social influences on eating

$\begin{array}{ll}\text { Friends make fun of my healthy eating } & 0.624\end{array}$

$\begin{array}{ll}\text { Partner makes fun of my healthy eating } & 0.537\end{array}$

$\begin{array}{ll}\text { Frequency of choosing food for free gift } & 0.476\end{array}$

Frequency of choosing food after celebrity endorsement $\quad 0.519$

Amount eaten

$\begin{array}{ll}\text { Frequency of eating everything in front of me } & 0.667\end{array}$

$\begin{array}{ll}\text { Frequency of finding it hard to stop eating a lot } & 0.657\end{array}$

$\begin{array}{lr}\text { Frequency of choosing largest size } & 0.583\end{array}$

Frequency of being a fussy eater 0.573

\section{Convenience food}

Type of food eaten at home (e.g. ready meals) -0.576

Knowing how to cook

Frequency of eating out

$-0.606$

Frequency of eating 'junk'

$-0.458$

Frequency of eating 'junk' food when out

$-0.453$

Frequency of eating fast food

$-0.693$

Frequency of eating take-aways

$-0.670$

Rather eat fast food than other

$-0.572$

Frequency of eating fried foods

$-0.530$

\begin{tabular}{llllll}
\hline Amount of variance explained; $\%$ & 23.6 & 8.1 & 6.0 & 5.4 & 4.7 \\
Eigenvalues for rotated solution & 6.9 & 4.3 & 2.1 & 2.2 & 5.6 \\
Cronbach's alpha (items, $n$ ) & $0.87(12)$ & $0.80(8)$ & $0.52(4)$ & $0.62(4)$ & $0.81(8)$
\end{tabular}

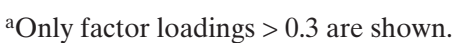

As the majority of excluded items had been based on the fourfactor solution, the excluded items were then reintroduced one at a time, to check whether any of these could increase the variance explained without detracting from the clarity of the solution. Frequency of eating out was the only item whose ad- dition helped clarify the five factors, however, this subsequently led to the removal of two additional items: finding it easy to eat healthily and the frequency of using vending machines. The final solution was therefore based on 37 items relating to dietary behaviour (table 1). This solution explained $47.8 \%$ of 
Table 2. Pearson's correlations of resulting factors with BMI, age, and BMI controlling for age

\begin{tabular}{lrrrrrr}
\hline Factor & BMI & p & Age & p & $\begin{array}{l}\text { BMI con- } \\
\text { trolling } \\
\text { for age }\end{array}$ \\
& & & & & $p$ \\
& & & & & & \\
\hline Healthy eating & 0.05 & 0.344 & -0.38 & $<0.001$ & 0.21 & $<0.001$ \\
Emotional eating & 0.15 & 0.004 & -0.25 & $<0.001$ & 0.26 & $<0.001$ \\
Social influences & -0.16 & 0.004 & -0.27 & $<0.001$ & -0.07 & 0.201 \\
Amount eaten & 0.20 & $<0.001$ & 0.08 & 0.155 & 0.19 & $<0.001$ \\
Convenience food & 0.09 & 0.103 & -0.42 & $<0.001$ & 0.07 & 0.214 \\
Physical activity & 0.36 & $<0.001$ & 0.05 & 0.388 & 0.37 & $<0.001$ \\
TV watching & 0.09 & 0.107 & -0.12 & 0.022 & 0.14 & 0.011 \\
Travel to work & 0.15 & 0.006 & 0.41 & $<0.001$ & 0.01 & 0.878 \\
Social influences & -0.09 & 0.093 & -0.13 & 0.018 & -0.05 & 0.344 \\
Mechanised transport & 0.31 & $<0.001$ & 0.13 & 0.018 & 0.28 & $<0.001$ \\
Dieting behaviour & 0.27 & $<0.001$ & 0.06 & 0.271 & 0.27 & $<0.001$ \\
Parents encourage activity & 0.13 & 0.018 & 0.00 & 0.959 & 0.13 & 0.013 \\
Alcohol consumption & -0.11 & 0.043 & 0.11 & 0.038 & -0.16 & 0.003 \\
Amount of sleep & 0.22 & $<0.001$ & 0.51 & $<0.001$ & 0.06 & 0.278 \\
Mother's weight/dieting & 0.05 & 0.335 & -0.16 & 0.002 & 0.10 & 0.066 \\
Father's weight/dieting & -0.02 & 0.703 & -0.31 & $<0.001$ & 0.11 & 0.057 \\
Early maturation & 0.07 & 0.143 & 0.13 & 0.014 & 0.03 & 0.626 \\
Breast-feeding & 0.03 & 0.616 & 0.11 & 0.042 & -0.01 & 0.819 \\
\hline
\end{tabular}

the variance and resulted in five clear factors which were easy to interpret. They represent: healthy eating behaviour; emotional eating (including snacking on junk food); social influences on eating; amount eaten; and convenience food (including eating out and eating fast, junk and pre-prepared foods versus knowing how to cook). Four of the 37 items loaded at higher than 0.3 on more than one factor: frequency of eating junk food (emotional eating: 0.458; convenience food:- 0.405), frequency of eating snacks (emotional eating: 0.536; convenience food: - 0.326), frequency of snacking on junk food (healthy eating: 0.410; emotional eating: 0.422 ), and frequency of feeling have eaten or drunk more than should (emotional eating: 0.530; amount eaten: 0.458 ). For the purposes of calculating reliability of factor scores, these items were included in the factor on which they loaded highest. As can be seen in table 1, healthy eating, emotional eating, and convenience food all showed good reliability (Cronbach's alpha $>0.80$ ). Amount eaten showed acceptable reliability (0.62) for a fouritem scale, but the reliability of the social influences (0.52) factor was less good. This may be explained by the fact that a number of items expected to be related to this factor (including eating with family) did not load highly on any factor and so were removed from the analysis, and the remaining items reflect fairly diverse influences on dietary behaviour (e.g. choosing food for a free gift and friends making fun when eat healthily). This factor may therefore benefit from the addition of other items.

\section{Calculation of Factor Scores}

Scores on the five factors were calculated as a weighted average of responses on all contributing items (i.e. those which had their highest loading on the factor, as shown in table 1). Weighted averages were used, as the number of available choices of response varied between items (3-6). Each item was therefore divided by the number of available responses for that item before an average score was calculated. The added advantage of using averages meant that if a response on any individual item was missing for a participant, an average for the relevant factor would still be calculated from the remaining items, thus maximising the available data.

\section{Correlation of Dietary Factors with BMI and Age}

The resulting factor scores were correlated with BMI using Pearson's r (table 2). All factors were correlated in the expected direction (i.e. with unhealthier behaviour related to higher BMI) with the exception of social influences on eating which was negatively correlated with BMI $(\mathrm{p}<0.01)$, i.e. those with higher BMI reported fewer negative social influences on their eating behaviour. More emotional eating $(\mathrm{p}<0.01)$ and selfreported higher amounts eaten $(\mathrm{p}<0.001)$ both showed modest associations with higher BMI. Healthy eating was not linearly associated with BMI, but further examination revealed that both underweight and obese respondents tended to report more unhealthy eating behaviours. There was no effect for convenience foods. Four of the five dietary factors were significantly related to age (table 2), and these associations were stronger than those with BMI $(0.25<\mathrm{r}<0.42)$. Younger respondents reported poorer healthy eating, more emotional eating, greater negative social influences on eating behaviour, and more use of convenience/fast foods (all p < 0.001). Only amount eaten was unrelated to age. For this reason, partial correlations controlling for age between the five dietary factors and BMI were carried out (table 2). The relationships of BMI with emotional eating and amount eaten remained significant $(p<0.001)$. Social influences were no longer significant, suggesting that the first-order effect was due to younger 
Table 3. Principle components analysis with Direct Oblimin rotation for current activity behaviour items $^{\text {a }}$

\begin{tabular}{|c|c|c|c|c|c|}
\hline & \multicolumn{5}{|l|}{ Factor } \\
\hline & $\begin{array}{l}\text { physical } \\
\text { activity }\end{array}$ & $\begin{array}{l}\text { TV } \\
\text { watching }\end{array}$ & $\begin{array}{l}\text { travel } \\
\text { to work }\end{array}$ & $\begin{array}{l}\text { social } \\
\text { influences }\end{array}$ & $\begin{array}{l}\text { mechanised } \\
\text { transport }\end{array}$ \\
\hline \multicolumn{6}{|l|}{ Physical activity } \\
\hline Frequency of half an hour a day activity & 0.754 & & & & \\
\hline Enjoy sport & 0.862 & & & & \\
\hline Frequency of organised sport & 0.772 & & & & \\
\hline Activity levels compared to others & 0.777 & & & & \\
\hline Importance of being physically fit & 0.758 & & & & \\
\hline Finding it easy to be physically active & 0.699 & & & & \\
\hline Frequency of preferring reading to walking etc & 0.453 & 0.346 & & & \\
\hline Frequency of exercise making me feel happier & 0.589 & & & & \\
\hline \multicolumn{6}{|l|}{$T V$ watching } \\
\hline Average hours of watching TV & & 0.820 & & & \\
\hline Frequency of snacking while watching TV & & 0.457 & & & \\
\hline TV watching compared to others & & 0.803 & & & \\
\hline Frequency of friends' encouragement to watch TV & & 0.404 & & 0.366 & \\
\hline Frequency of watching TV while eating & & 0.616 & & & \\
\hline
\end{tabular}

Travel to work

Frequency of travelling to school/work by car or bus

$-0.904$

Frequency of walking or cycling to school/work

$-0.865$

Social influences

Frequency of friends making fun when I am active $\quad 0.834$

Frequency of partner making fun when I am active $\quad 0.839$

Mechanised transport

Frequency of travelling by car for journeys up to 1 mile $\quad-0.845$

Frequency of walking for journeys up to one mile -0.846

Frequency of taking lift or escalator in lieu of stairs -0.410

\begin{tabular}{lccccc}
\hline Amount of variance explained, \% & 23.5 & 10.7 & 10.2 & 7.8 & 6.9 \\
Eigenvalues for rotated solution & 4.5 & 2.4 & 2.0 & 1.6 & 2.2 \\
Cronbach's alpha (items, $n$ ) & $0.87(8)$ & $0.62(5)$ & $0.83(2)$ & $0.69(2)$ & $0.61(3)$
\end{tabular}

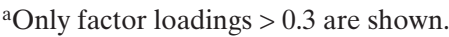

respondents having lower BMI but also reporting more negative social influences on dietary behaviour. Once age was controlled for, there was also a significant, though modest, effect of healthy eating $(\mathrm{r}=0.21, \mathrm{p}<0.001)$, with those reporting less healthy eating having higher BMI. The first-order non-significant relationship between healthy eating and BMI was therefore masking the fact that younger respondents had lower BMI and also reported less healthy eating. Healthy eating had a clear effect on BMI when this relationship was partialled out. Once again, there was no relationship between BMI and frequency of preference for convenience foods.

\section{Activity Items}

Factor Analysis and Reliability Testing

All items $(n=26)$ relating to current activity behaviour were entered into a PCA. (Note: the items relating to parents liking the respondent to be active whilst growing up were excluded from the activity factor analysis as they do not relate to current activity behaviour but rather may form part of the developmental process. When they were included, they formed a clear additional factor on which no other items loaded.) There were 7 factors with eigenvalues $>1$ together explaining $60.0 \%$ of the variance. However, a scree plot suggested a five-factor solution might be more appropriate. The PCA was rerun specifying a five-factor extraction, and Direct Oblimin rotation was used in order to help clarify the solution, whilst allowing the resulting factors to be correlated. The resulting five-factor solution explained $52.0 \%$ of the total variance.

Two items (relating to feeling lazy and fidgeting) did not load highly $(>0.3)$ on any of the resulting five factors, and these were then excluded and the PCA analysis rerun. This resulted in a solution explaining $54.7 \%$ of the variance. However, there was an issue in this adult sample surrounding TV in bedroom/computer usage and travel to work/college school: with 
the first two items loading highly in a negative direction (i.e. less frequent or 'good' activity behaviour) and the latter in a positive direction (i.e. more frequent car usage or 'bad' activity behaviour) on the same factor. This suggests an age effect: older workers are more likely to drive to work and less likely to play computer games or have a TV/computer in their bedroom. For this reason, the analysis was repeated excluding two items relating to having a TV/computer in bedroom and playing computer games for this adult sample. (Note: if the questionnaire were to be used with children or adolescents, these two items may be important predictors of overall activity behaviour.) When these items were excluded, $57.2 \%$ of the variance was explained, and the resulting factors were clearly defined. They related to physical activity/sport, TV watching, travel to work, social influences on activity, and use of mechanised transport. We were somewhat surprised that travel to work and use of mechanised transport loaded on separate factors in this sample. Forcing a four-factor solution did result in these items loading on one-factor, but it also resulted in a number of other items loading highly on more than 1 of the resulting factors, and the solution was therefore less easy to interpret; hence, the five-factor solution is preferred. Finally, it was noted that the two items relating to playing sport with family and friends only loaded on the physical activity and not on the social influences factor; removing these resulted in a very similar solution to when they were included, whilst satisfying our aim of reducing the total items in the questionnaire. The final solution was therefore based on 20 items relating to current activity behaviour (table 3 ). This solution explained $59.1 \%$ of the variance. Two items (friends encouragement of TV watching and rather read than walk) loaded on two factors, and these have been included in the factor on which they loaded highest for the purposes of reliability analysis and calculation of factor scores. As can be seen in table 3, physical activity and travel to work showed good reliability (Cronbach's alpha $>0.80)$, whilst the other three factors showed acceptable reliability $(\geq 0.62)$ for factors based on only $2-5$ items.

\section{Correlation of Activity Factors with BMI and Age}

The resulting scores (calculated as for dietary factor scores above) on the five factors were correlated with BMI using Pearson's r (table 2). All factors were correlated in the expected direction with the exception of social influences on activity which was negatively correlated with BMI, i.e. those with higher BMI reported less negative influences on their activity behaviour, although this did not reach significance. Less physical activity/sport $(\mathrm{p}<0.002)$ and higher use of mechanised transport $(\mathrm{p}<0.001)$ were both clearly associated with higher BMI, whilst there was also a significant, though modest, association with more usage of car/bus etc. for travel to work $(\mathrm{p}<0.01)$. There was no effect for TV watching. A number of the activity factors were significantly related to age (table 2): younger respondents reported much less usage of car/bus/train to travel to work or college $(\mathrm{p}<0.001)$ as well as less usage of mechanised transport, more TV watching, and greater negative social influences on activity (all modest effects, $\mathrm{p}<0.05$ ). There was no effect of age on physical activity. Partial correlations, controlling for age, between the five activity factors and BMI were carried out (table 2). Physical activity and use of mechanised transport (both $\mathrm{p}<0.001$ ) remained highly significant, and TV watching also showed a significant, though modest, effect once age was controlled for $(\mathrm{p}<0.05)$, with those watching more TV having higher BMI. In contrast, travel to work was no longer significant, suggesting the effects found for firstorder correlations in this sample were due to younger respondents, who are more likely to walk or cycle to work, also having lower BMI.

\section{Other Behaviours}

Factor Analysis and Reliability Testing

Finally, the remaining questionnaire items were included in a third exploratory factor analysis. In this analysis, Varimax instead of Direct Oblimin rotation was used as it was not expected that the resulting factors should be related. As there was only a single item on breastfeeding, this was not included in the PCA, but was correlated with BMI separately. The item 'I usually go to sleep at (choice of times)', was also excluded: this was found to be negatively related to one of the other sleep items, and responses on this item were skewed, with almost two-fifths of respondents reporting 'after midnight' suggesting there was insufficient discrimination in the predetermined choices. This will be amended in future versions of the questionnaire. In addition, fewer than $2 \%$ of respondents reported any use of diet pills or laxatives as an aid to weight loss, and so this item was also excluded. Seven clear factors were identified from the remaining 16 items, together explaining $72.1 \%$ of the variance (table 4). They represent: dieting behaviour; early maturation; parental encouragement to be active (whilst growing up); amount of sleep; alcohol consumption; mother's weight/dieting behaviour (including perceived overweight and dieting behaviour) and father's weight/dieting behaviour. As the additional items in the modified questionnaire (relating to past dieting behaviour and average weekly alcohol units) are included in this analysis, the sample size is notably reduced: however, when these items were excluded, the seven factor solution was similarly supported in the larger sample. The reliability scores for parental encouragement to be active, alcohol consumption, and dieting behaviour were good (all $>0.70$ ), amount of sleep was adequate (0.62), whilst father's weight/ dieting behaviour $(0.50)$, early maturation (0.41), and mother's weight/dieting behaviour (0.41) were relatively poor. This suggests that the latter 3 factors, which all consist of two relatively diverse items (e.g. perception of parental weight and dieting behaviour), could benefit from the addition of other items. 
Table 4. Principle components analysis with Varimax rotation for remaining items ${ }^{\mathrm{a}}$

\begin{tabular}{|c|c|c|c|c|c|c|c|}
\hline & \multicolumn{7}{|l|}{ Factor } \\
\hline & $\begin{array}{l}\text { dieting } \\
\text { behaviour }\end{array}$ & $\begin{array}{l}\text { parents } \\
\text { encourage } \\
\text { activity }\end{array}$ & $\begin{array}{l}\text { alcohol } \\
\text { con- } \\
\text { sumption }\end{array}$ & $\begin{array}{l}\text { amount } \\
\text { of sleep }\end{array}$ & $\begin{array}{l}\text { mother's } \\
\text { weight/ } \\
\text { dieting }\end{array}$ & $\begin{array}{l}\text { father's } \\
\text { weight/ } \\
\text { dieting }\end{array}$ & $\begin{array}{l}\text { early } \\
\text { maturation }\end{array}$ \\
\hline Frequency of dieting or exercising to lose weight & 0.841 & & & & & & \\
\hline Frequency of dieting or exercising to stay same weight & 0.625 & & & & & & \\
\hline Frequency of success when dieting & 0.690 & & & & & & \\
\hline Frequency of regaining weight when dieting & 0.798 & & & & & & \\
\hline Frequency of father liking me to be physically active & & 0.914 & & & & & \\
\hline Frequency of mother liking me to be physically active & & 0.910 & & & & & \\
\hline Frequency of drinking alcohol & & & 0.914 & & & & \\
\hline Average weekly alcohol units & & & 0.891 & & & & \\
\hline Usual number of hours sleep & & & & 0.855 & & & \\
\hline Usual time of waking up & & & & 0.826 & & & \\
\hline Mother's weight whilst I was growing up & & & & & 0.759 & & \\
\hline Frequency of mother trying to lose weight & & & & & 0.771 & & \\
\hline Father's weight whilst I was growing up & & & & & & 0.769 & \\
\hline Frequency of father trying to lose weight & & & & & & 0.834 & \\
\hline Weight at birth (category) & & & & & & & 0.719 \\
\hline Height at 7 years old compared to others & & & & & & & 0.834 \\
\hline Amount of variance explained, \% & 14.1 & 11.1 & 10.7 & 9.6 & 9.1 & 8.9 & 8.5 \\
\hline Eigenvalues for rotated solution & 2.3 & 1.8 & 1.7 & 1.5 & 1.5 & 1.4 & 1.4 \\
\hline Cronbach's alpha (items, $n$ ) & $0.72(4)$ & $0.83(2)$ & $0.82(2)$ & $0.61(2)$ & $0.41(2)$ & $0.50(2)$ & $0.41(2)$ \\
\hline
\end{tabular}

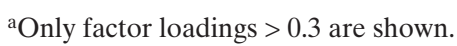

Correlation of other Behaviour Factors with BMI and Age

Scores on the seven factors were calculated as weighted averages as described for the dietary factors above. The seven factors, along with the single breastfeeding item, were then correlated with BMI (table 2). Higher BMI was significantly related to more frequent/less successful dieting behaviour and lower amount of sleep (both $\mathrm{p}<0.001$ ), and there was also a modest association with less parental encouragement to be physically active $(\mathrm{p}<0.05)$. Earlier maturation was also positively related to higher BMI, although this was not significant. Maternal weight/dieting behaviour, paternal weight/dieting behaviour, and breastfeeding were unrelated to BMI. Consumption of alcohol was correlated with BMI in an unexpected direction: there was a modest association of higher BMI with less alcohol consumption $(\mathrm{p}<0.05)$.

A number of these factors were significantly related to age (table 2): older respondents reported much less sleep and far healthier father's weight/behaviour (lower weight and/or less dieting) (both $\mathrm{p}<0.001$ ), and there were more modest associations between older age and healthier mother's weight/ behaviour ( $\mathrm{p}<0.01)$; more alcohol consumption; earlier maturation; and less likelihood of being breastfed (all $\mathrm{p}<0.05$ ). BMI was therefore correlated with the seven factors controlling for age (table 2). Less parental encouragement to be active $(\mathrm{p}<0.05)$, more frequent/less successful dieting behaviour ( $\mathrm{p}<0.001)$, and lower alcohol consumption $(\mathrm{p}<0.01)$ remained significantly related to higher BMI. Once age was con- trolled for, healthier mother's weight/dieting behaviour $(\mathrm{p}=0.066)$ and father's weight/dieting behaviour $(\mathrm{p}=0.057)$ were now related to lower BMI, although both only approached significance. This suggests that the tendency of younger respondents to report poorer parental weight/dieting behaviour in this sample could have masked any association between parental weight factors and higher BMI. Finally, once age was controlled for, there was no relationship between sleep and BMI. This suggests that the first order relationship was a reflection of the fact that younger respondents reported sleeping more, and also had lower BMI.

\section{Discussion}

This follow-up to a pilot study of a questionnaire measuring multiple risk factors for obesity has shown the measure has good psychometric properties as well as significant relationships with BMI. The factor structure for activity and diet and other factors expected to relate to obesity was clearly defined and easy to interpret. Further, the PCA resulted in a reduction from 103 items to 74 in the final solution. However, a number of 2-item factors did not show good internal reliability, and could benefit from the addition of further items. In addition, some of the deleted items, such as playing computer games, whilst not contributing to the solution in this adult population, may still be important in examining obesity in adolescent samples, and so further work on 
questionnaire refinement is needed. Nonetheless, the development of this questionnaire is an important step towards understanding the relevant importance of these various factors in the tendency to overweight and obesity, and the results confirm that a self-report measure can have merit in this area.

For the whole sample, the strongest associations between the scale's sub-factors and higher BMI were for: the tendency to eat higher amounts of food; lower levels of physical activity; greater use of car, bus, escalators etc. as opposed to walking or cycling; more frequent/unsuccessful dieting behaviour; and having less sleep. Significant associations were also found in the expected direction between BMI and emotional eating, mode of transport to work, and parental encouragement to be active whilst growing up. All of these effects have been found in previous research $[6,8,10,14,17,21,28]$, but, to our knowledge, no other study has examined all of these diverse elements in relation to BMI using one, comprehensive measure. Unexpected correlations were found between higher BMI and drinking less alcohol, and lower BMI and reporting more negative social influences on dietary and activity behaviour. The latter are explained by the fact that negative social influences were higher amongst younger adults who also had lower BMI. However, the effects of age cannot explain the former: although there was an association between age and alcohol consumption with younger adults tending to report lower levels, the association between having higher BMI and reporting lower alcohol consumption remained once age was controlled for. This is in contrast to other findings that obesity is associated with higher alcohol consumption [38]. One possible explanation in this sample is that cutting out alcoholic drinks is used as a weight control measure by heavier individuals, as they may be viewed as 'empty calories'. It is also feasible that alcohol consumption in overweight adults suffered from the same reporting bias as food consumption [36].

There were no significant first-order effects for healthy eating, use of convenience foods, early maturation, breastfeeding, and parental weight/dieting behaviour, in contrast to some earlier studies [16, 22-26, 39]. However, age effects may have masked associations between BMI with healthy eating, TV watching, and parental weight/dieting behaviour, as noted below.

The age effects found were of particular interest. Younger adults generally reported poorer health behaviours including: less healthy eating, more emotional eating, greater negative social influences on eating and activity behaviours, more use of convenience foods, more TV watching, and less healthy weight/dieting behaviour for both parents. Our results support previous findings regarding unhealthier dietary behaviour, susceptibility to outside influences in making health choices, and more TV watching in adolescents and younger adults [39, 40]. In contrast, younger adults in our study reported more healthy behaviour with regard to travel to work, less use of mechanised transport, more sleep, and later maturation, but there were no significant age effects for physical activity (including exercise) participation. The latter was surprising, as it is generally accepted that participation in physical activity, including sport, declines with age [2,39]. Once these age differences were controlled for, healthy eating and TV watching were significantly related to BMI in the expected direction, whilst sleep was no longer significant: in other words, the tendency to sleep longer was only related to BMI insomuch as younger adults both exhibited this behaviour and had lower BMI. The fact that younger adults (who had lower BMI) report lower frequency of eating healthy foods initially masked an association between this behaviour and higher BMI. Once age was controlled for, those reporting less frequency of healthy eating also had higher BMI.

It must be of concern to health professionals aiming to counter the obesity epidemic that younger adults consistently reported unhealthier behaviours, which appear only marginally offset by greater daily activity and more sleep. What we cannot tell from this cross-sectional study is whether eating and activity behaviours will tend to become healthier as these younger respondents mature and become more conscious of their own health and health issues. If they do not, then this could indicate serious consequences for future obesity levels and their impact on health services.

We must not forget that these are self-report data which may be subject to biased reporting, especially eating behaviours by obese individuals [36]. However, it was interesting to note that those with higher BMI did report more emotional eating and amount eaten, which suggests that careful choice of questions may be able to elicit a fairly accurate picture of behaviours related to obesity. However, it could be argued that some of the items, especially with regard to eating too much, may be a reflection of an obese individual's self-view perpetuated by society's insistence that we are responsible for our own weight and that the overweight are therefore 'greedy'. There was less evidence of potentially biased reporting in activity levels, perhaps because current media reports appear to emphasise the link between obesity and food rather more than exercise, and the negative stigma associated with not taking part in sport is less marked than that related to overeating. Nonetheless, despite the problematic nature of self-report data in this area, once age was controlled for, there was a strong association between eating less healthy foods and higher BMI, as was expected.

\section{Limitations}

This was a skewed sample with regard to age, due to the high proportion of student respondents, and the working adults were also biased towards higher SES: these two combined likely explained the lower proportions of overweight and obese adults than are now reported in UK national studies. It is possible that a different factor structure could emerge in different socio-economic and age groups, and so further research is needed to ensure the results replicate. It also appeared that this age bias masked some relationships with BMI, which we 
were able to account for by using partial correlations controlling for age. However, different associations may be found in a less age-biased sample. This report only examined individual associations of the resulting factors with BMI; further analysis of the current sample in order to assess the relative risks of these factors is currently ongoing.

\section{Conclusion}

The further development of this self-report measure of multiple risk factors for obesity, which showed good psychometric properties and a clear factor structure, is an important step towards understanding the relevant importance of these various factors in the tendency to overweight and obesity.

\section{Practice Implications}

The finding that younger respondents tended to exhibit less healthy dietary and activity behaviours, reaffirms the need to develop early intervention programmes to ensure these unhealthy behaviours are tackled early, and certainly before these young adults have become overweight or obese.

\section{References}

1 World Health Organisation: Diet, nutrition and the prevention of chronic diseases. WHO Technical report series, 911. Geneva, WHO, 2003.

2 Office for National Statistics and Medical Research Council: National Diet and Nutrition Survey: Adults aged 19-64 years. Volume 4: Nutritional status (anthropometry and blood analytes), blood pressure and physical activity. London, TSO, 2004.

3 Foresight (2007): Tackling obesity. Future Choices. Modelling future trends on obesity and their impact on health. www.foresight.gov.uk/Obesity/17.pd

4 Must A, Spadano J, Coakley EH, Field AE, Colditz G, Dietz WH: The disease burden associated with overweight and obesity. JAMA 1999;282:1523-9.

$\checkmark 5$ Gortmaker SL, Must A, Perrin JM, Sobol MA, Dietz WH: Social and economic consequences of overweight in adolescence and young adulthood. N Engl J Med 1993;329:1008-12.

6 Prentice AM, Jebb SA: Obesity in Britain: gluttony or sloth? Brit Med J 1995;311:437-9.

7 Pinhas-Hamiel O, Zeitler P: 'Who is the wise man? The one who foresees consequences:' Childhood obesity, new associated comorbidity and prevention. Prev Med 2000;31:702-5.

8 Lobstein T: Obesity in children and young people: a crisis in public health. Obes Rev 2004;5(suppl 1):4 85.

9 Ministry of Agriculture, Fish and Food: Household Food Consumption and Expenditure. London, HMSO, 1992.

10 Rolls BJ, Morris EL, Roe LS: Portion size of food affects energy intake in normal-weight and overweight men and women. Am J Clin Nutr 2002;76: 1207-13.

11 Hill JO, Melanson EL, Wyatt HT: Dietary fat intake and regulation of energy: Implications for obesity. J Nutr 2002;130:S284-8.

12 Ludwig DS, Peterson KE, Gortmaker SL: Relation between consumption of sugar-sweetened drinks and childhood obesity: a prospective observational analysis. Lancet 2001;357:505-8.

13 Kimm SY: The role of dietary fiber in the development and treatment of childhood obesity. Pediatrics 1995;96:1010-4.

14 French SA, Jeffrey RW, Forster JL, McGovern PG, Kelder SH, Baxter JR: Predictors of weight change over two years among a population of working adults: The healthy worker project. Int J Obes 1994; 18:145-54.
15 Mellin AE, Neumark-Sztainer D, Story M, Ireland M, Resnick MD: Unhealthy behaviors and psychosocial difficulties among overweight adolescents: the potential impact of familial factors. J Adolesc Health 2002;31:145-53.

16 Ma Y, Bertone ER, Stanek EJ 3rd, Reed GW, Herbert JR, Cohen NL, Merriam PA, Ockene IS: Association between eating patterns and obesity in a free-living US adult population. Am J Epidemiol 2003; 158:85-92.

17 Tuomisto T, Tuomisto MT, Hetherington M, Lappalainan R: Reasons for initiation and cessation of eating in obese men and women and the affective consequences of eating in everyday situations. Appetite 1998;30:211-22

18 Gortmaker SL, Must A, Sobol AM, Peterson K, Colditz GA, Dietz WH: Television viewing as a cause of increasing obesity among children in the United States, 1986-1990. Arch Pediatr Adolesc Med 1996;150:356-62.

19 Robinson TN: The 30-second effect: an experiment revealing the impact of television commercials on food preferences of preschoolers. J Am Diet Assoc 2001;101:42-6.

20 Coon KA, Goldberg J, Rogers BL, Tucker KL: Relationships between use of television during meals and children's food consumption patterns. Pediatrics 2001;107:e7.

21 Jebb SA, Moore MS: Contribution of a sedentary lifestyle and inactivity to the etiology of overweight and obesity: current evidence and research issues. Med Sci Sports Exerc 1999;31(suppl 11):S534-41.

22 Whitaker RC, Wright JA, Pepe MS, Seidel KD, Dietz WH: Predicting obesity in young adulthood from childhood and parental obesity. N Engl J Med 1997;337:869-73.

23 Maes HH, Neale MS, Eaves LJ: Genetic and environmental factors in relative body weight and human adiposity. Behav Genet 1997;27:325-51.

24 Whitaker RC, Dietz WH: The role of the environment in the development of obesity. J Pediatr 1998; 132:768-76.

25 Van Lenthe FJ, Kemper HCG, van Mechelen W: Rapid maturation in adolescence results in greater obesity in adulthood: the Amsterdam Growth and Health Study. Am J Clin Nutr 1996;64:18-24.

26 Von Kries R, Kolezo B, Sauerweld T, von Mutius E, Barnert D, Grunert V, von Voss H: Breast feeding and obesity: cross sectional study. Brit Med J 1999; 319:147-50.
27 Hardy R, Wadsworth M, Kuh D: The influence of childhood weight and socioeconomic status on change in adult body mass index in a British national birth cohort. Int J Obes Relat Metab Disord 2000;24:725-34.

28 Hasler G, Buysse DJ, Klaghofer R, Gamma A, Ajdacic V, Eich D, Rossler W, Angst J: The association between short sleep duration and obesity in young adults: a 13-year prospective study. Sleep 2004;27:661-6.

29 Wake M, Hesketh K, Waters E: Television, computer use and body mass index in Australian primary school children. J Pediatr Child Health 2003;39: 130-4.

30 Müller MJ, Nast M, Asbeck K, Langnäse, Grund A: Prevention of obesity - is it possible? Obes Rev 2001;2:15-28.

31 Chambers JA, Swanson V: A health assessment tool for multiple risk factors for obesity: results from a pilot study with UK adults. Pat Educ Counsel 2006; 62:79-88.

32 Office of Population and Census Surveys (OPCS): Classification of Occupations. London, HMSO, 1991.

33 World Health Organisation: Health and Health Behaviour among Young People. Who Policy Series: Health Policy for Children and Adolescents: Series No. 1. Geneva, WHO, 2000

34 Wardle J, Guthrie CA, Sanderson S, Rapoport L: Development of the Children's Eating Behaviour questionnaire. J Child Psychol Psychiatry 2001;42: 963-70.

35 Flesch RF: A new readability yardstick. J App Psychol 1948;32:221-33.

36 Heitman BL, Lissner L: Dietary underreporting by obese individuals - is it specific or non-specific? Brit Med J 1995;311:986-9.

37 Groessl EJ, Kaplan RM, Barrett-Connor E, Ganiats TG: Body mass index and quality of well-being in a community of older adults. Am J Prev Med 2004; 26:126-9.

38 Scottish Executive: The Scottish Health Survey 2003 - Volume 2. Edinburgh, Blackwell, 2003.

39 Greenwood JLJ, Stanford JB: Preventing or improving obesity by addressing specific eating patterns. J Am Board Fam Med 2008;21:135-40.

40 Kurtz ME, Kurtz JC, Johnson SM, Cooper W: Sources of information on the health effects of environmental tobacco smoke among AfricanAmerican children and adolescents. J Adol Health 2001;28: 458-64. 